\title{
COVID-19: experiences of lockdown and support needs in children and young adults with kidney conditions
}

\author{
Yincent Tse ${ }^{1}$ (D) Anne-Sophie E. Darlington ${ }^{2} \cdot$ Kay Tyerman $^{3} \cdot$ Dean Wallace $^{4} \cdot$ Tanya Pankhurst $^{5} \cdot$ Sofia Chantziara $^{2}$. \\ David Culliford $^{6} \cdot$ Alejandra Recio-Saucedo $^{7} \cdot$ Arvind Nagra $^{8}$
}

Received: 10 January 2021 / Revised: 19 February 2021 / Accepted: 2 March 2021 / Published online: 19 March 2021

(C) Crown 2021

\begin{abstract}
Background During the initial COVID-19 pandemic, young United Kingdom (UK) kidney patients underwent lockdown and those with increased vulnerabilities socially isolated or 'shielded' at home. The experiences, information needs, decision-making and support needs of children and young adult (CYA) patients or their parents during this period is not well known.

Methods A UK-wide online survey co-produced with patients was conducted in May 2020 amongst CYA aged 12-30, or parents of children aged $<18$ years with any long-term kidney condition. Participants answered qualitative open text alongside quantitative closed questions. Thematic content analysis using a three-stage coding process was conducted.

Results One-hundred and eighteen CYA (median age 21) and 197 parents of children (median age 10) responded. Predominant concerns from CYA were heightened vigilance about viral (68\%) and kidney symptoms (77\%) and detrimental impact on education or work opportunities (70\%). Parents feared the virus more than CYA (71\% vs. $40 \%)$, and had concerns that their child would catch the virus from them (64\%) and would have an adverse impact on other children at home (65\%). CYA thematic analysis revealed strong belief of becoming seriously ill if they contracted COVID-19; lost educational opportunities, socialisation and career development; and frustration with the public for not following social distancing rules. Positive outcomes included improved family relationships and community cohesion. Only a minority (14-21\% CYA and 20-31\% parents, merged questions) desired more support. Subgroup analysis identified greater negative psychological impact in the shielded group.

Conclusions This survey demonstrates substantial concern and need for accurate tailored advice for CYA based on individualised risks to improve shared decision making.
\end{abstract}

Keywords Age $\cdot$ Paediatrics $\cdot$ Quality of life $\cdot$ COVID-19

\section{Introduction}

On 23 March 2020, in response to the COVID-19 pandemic, the UK entered a continuous period of 'lockdown', with

Y. Tse and A. S. Darlington contributed equally to the study.

\section{Yincent Tse}

yincenttse@nhs.net

1 Great North Children's Hospital, Newcastle Upon Tyne, UK

2 School of Health Sciences, University of Southampton, Southampton, UK

3 Department of Paediatric Nephrology, Leeds Children's Hospital, Leeds, UK closure of schools, workplaces and restrictions on outdoor movements other than exercise or essential shopping. Studies into the experiences of families under quarantine for previous pandemics (SARS-CoV-1, MERS) and in Chinese

4 Department of Paediatric Nephrology, Royal Manchester Children's Hospital, Manchester, UK

5 University Hospitals Birmingham NHS Foundation Trust, Edgbaston, Birmingham, UK

6 NIHR Applied Research Collaboration Wessex, School of Health Sciences, University of Southampton, Southampton, UK

7 Faculty of Medicine, University of Southampton, Southampton, UK

8 Southampton Children's Hospital, Southampton, UK 
adolescents during COVID-19 showed very high levels of traumatic distress $[1,2]$. Prior to the current pandemic, children and young adults (CYA) with chronic kidney diseases (CKD) already had well-established psycho-social vulnerabilities; most studies reported a greater rate of social and behavioural problems with adjustment disorders, depression, anxiety and neurocognitive disorders compared to their peers [3-5]. They were less likely to be in a relationship, more likely to live in the family home, receive no income, be unable to work due to ill-health and have worse well-being than peers in the general population $[6,7]$.

Early during the UK epidemic, the government issued a list of conditions and associated treatment regimens considered to constitute extreme clinical vulnerability to COVID-19 disease [8]. For kidney patients, regardless of age, these initially included those requiring dialysis, or on immunosuppression, e.g. kidney transplant recipients and non-transplant indications at an arbitrary level which changed several times during the pandemic. They were recommended to 'shield', i.e. to remain at home at all times, and have no face-to-face contact with anyone outside of their household [9].

During this period of prolonged lockdown, it became evident that the potential harms of COVID-19 (the disease caused by the virus SARS-CoV-2) to CYA even with severe comorbidities were not only from the virus itself but also from being kept at home and away from friends, education or fledgling careers [1]. Fortunately, in stark contrast to the devastating $31 \%$ mortality rate in the over 40 -year age kidney transplant recipients, there were no deaths reported in under 40year-olds [10]. The impact of missing education in CYA with CKD who already have lower cognition compared with the general population is unknown, and there is also significant concern about the gaps in safeguarding protection when vulnerable children are not visible to teachers [11, 12].

Little is known about the concerns and decision-making in this young patient group, especially given the rapidly evolving instructions in the early stages of the pandemic. Existing professional networks of charities, clinicians, academics, parents, young patients and young adults were mobilised to develop this study with the aims of increasing our understanding of the evolving experiences, information needs and decision-making in CYA and parents of children living with a kidney condition.

\section{Methods}

\section{Study design}

A survey of CYA with a kidney condition (12-30 years) and parents with children aged $0-18$ years who have kidney conditions, assessing experiences, information and support needs and decision-making was undertaken. The survey was coproduced in its design, piloting and dissemination by CYA, parents, clinicians, youth workers and patient advocacy groups. Due to time pressure and socially distancing regulations, CYA representatives were recruited from personal contacts and video focus groups held to refine survey questions before dissemination.

The survey opened between 11 May and 1 June 2020, during the initial wave (including lockdown) of the COVID-19 pandemic within the UK. On 1 June we closed the survey to coincide with the first significant UK easing of lockdown reopening schools and permitting people to meet outdoors. The study was approved by University of Southampton and UK NHS Health Research Authority Research Ethics Committees (IRAS nr. 282176).

Whilst SARS-CoV-2 refers to the virus and COVID-19 refers to the clinical disease, during co-design, we found that this distinction was not appreciated by many non-medical people. For this reason, the questionnaires referred to COVID-19 to cover the virus and the disease. For convenience, the term is used in this way throughout the paper.

\section{Participants}

Participants were CYA who self-identified they were affected 'with any long-term kidney condition' aged between 12 and 30 years, or parents/guardian of a child aged between 0 and 18 years, able to read and respond in English. Participants were recruited from across the UK by healthcare teams, national kidney charities, targeted closed Facebook groups and social media. The survey was available either as a link or via poster QR code accessible on a PC, tablet or smartphone. Electronic consent was obtained before completing the online survey. Up to 200 respondents (parents) and 100 young people were intended to be recruited to ensure sufficient numbers of participants to map the range of issues and experiences [13], identify common issues across them, carry out meaningful subgroup analyses and provide rich data from the open text qualitative responses $[14,15]$.

\section{Survey}

The core set of questions was based on currently available literature [16-18], expert clinician input, co-produced with CYA and parents of a child with cancer $(n=7)$ and then adapted by parents and CYA with a kidney condition $(n=$ 13). Further refinement was performed over two videoconference focus groups with a small number of CYA charity group representatives $(n=3)$ who clarified any contentious questions with their groups to come up with the final survey. We sought opinion on content, phrasing, usability and value of each question for research. The survey consisted of two sections consisting of (a) qualitative open questions and (b) quantitative closed statements. 
Seven open questions were asked: Experiences: Can you tell us about your experiences and views on the virus in relation to your child with a kidney condition?; Hospital: I worry the hospital is no longer a safe place during the virus outbreak-if so in what way?; Positive aspects: I have experienced some positive things to come out of the virus outbreak, either at home or related to care, if so in what way?; Mood: In relation to the virus outbreak, my mood or behaviour has changed, if so in what way?; Information: Can you tell us where you get information on the virus and what other information you might need?; Decisions: Can you tell us how you make decisions about looking after your child in relation to the virus?; and Support: What additional support would you like, at home or in hospital, in relation to the virus?. These open questions were intended to be completed prior to the closed statements which guided the respondent's thinking. A final free text question asked respondents whether they had any further comments.

The closed statement items were in the following domains: Experiences $(n=13)$, Information $(n=7)$, Decisions $(n=10)$ and Support needs $(n=5)$. A small number of items differed between the parent and CYA surveys. Response options were Not at all, A little, Quite a bit and Very much (except for two conditional questions with Yes/No as response options). For simplicity, COVID-19 was referred to as 'the virus'. Demographic information was also collected, such as age and treatment.

\section{Data analysis}

The qualitative open questions data were subjected to a thematic content analysis, informed by a three-stage coding process $[19,20]$ : Stage 1: Initial samples were open-coded into broad comment categories by two researchers (SC, AR), refining an existing framework, and resolving any conflicts with a third researcher (ASD); Stage 2: The framework was used to categorise all comments from the data, with further refinement; and Stage 3: Overarching themes were identified from analysis of similarities in the content between categories. Number of comments were counted, to identify weight of themes. Because of the overlap in comments to categories, the total number of comments does not match the number of participants. Illustrative quotes that most represented each subtheme were chosen by consensus (SC, AR, ASD).

Descriptive statistics were carried out using IBM Statistical Package for Social Science (SPSS) to summarise the demographic data for the two participant groups, and undertake simple descriptive statistics of the closed statement items (collapsing the lowest two response options (Not at all, A little) and the highest two response options (Quite a bit, Very much) into a binary outcome). Subgroup analyses were carried out on an item level, using chi-squared analyses at the two-sided significance level $p<0.05$, according to whether young people were in the shielded group (instruction from UK Government to stay isolated) or not, separately for the CYA and parent samples. No subgroup analyses were carried out according to age.

\section{Results}

\section{Participants}

One-hundred and eighteen CYA with kidney conditions answered the survey, median age was 21 years (range 12-30 years) with 40 (33.9\%) under 18 years old. Respondents' ethnicities were similar to age-matched prevalent Renal Registry patient cohort with 96 (81.4\%) identifying as white.

One-hundred and ninety-seven parents completed the survey, the majority mothers $(n=169,85.8 \%)$ and of white ethnicity $(n=186,94.4 \%)$. The median age of the children of responding parents was 10 years (range 0-18 years). Table 1 summarises respondents' characteristics.

\section{Quantitative results from survey responses}

The study generated quantitative results from the closed statement items, which are presented as those who responded with 'Quite a bit' or 'Very much' for both CYA (Fig. 1) and parents (Fig. 2). Subgroup analyses, comparing those who were shielded with those who were not, are also included.

The majority of CYA were vigilant about virus symptoms (68\%) or 'kidney' symptoms (77\%), whilst $40 \%$ worried about the virus. For $70 \%$ of CYA, education and work had been impacted. Information came from their clinical team $(45 \%)$ or through accessing social media $(75 \%)$. Sixty-one percent of CYA reported being seen less by their clinical team compared to before the pandemic.

Most parents worried about the virus (72\%), or were vigilant about virus symptoms (83\%) or kidney symptoms (87\%). Over half of the parents (57\%) felt protected with the shielding advice. Information came from clinical teams (43\%) but more from social media (67\%). A third of those who accessed information through social media were left feeling anxious (31\%). Parents worried that their child would catch the virus from them $(65 \%)$ and worried about the impact on other children at home $(66 \%)$. Only a small minority reported that they would like more support from an educational institution (CYA $14 \%$, parents $20 \%$ ) or support to reduce worries (CYA $21 \%$, parents $31 \%$ ).

\section{Shielded vs. non-shielded patients}

Results of subgroup analyses that assessed differences between the shielded and non-shielded groups are summarised in Figs. 1 and 2. Over half of CYA, either responding 
Table 1 Respondent characteristics

\begin{tabular}{lll}
\hline Surveys & Children and young Adults (CYA) & Parents/guardian \\
\hline Completed by, $n$ & 118 & 197 \\
Participant age, years, median (range) & $21(12-30)$ & $41(21-60)$ \\
Child's age, years, median (range) & & $10(0-18)$ \\
Ethnicity, $n(\%)$ & & \\
White & $96(81.4 \%)$ & $186(94.4 \%)$ \\
Asian & $9(7.6 \%)$ & $6(3.0 \%)$ \\
Black & $3(2.5 \%)$ & 0 \\
Mixed & $6(5.1 \%)$ & $3(1.5 \%)$ \\
Other & $3(2.5 \%)$ & $2(1.0 \%)$ \\
Missing & $1(0.8 \%)$ & 0 \\
CYA in shielded group, $n(\%)$ & & $113(57.4 \%)$ \\
Yes & $73(61.9 \%)$ & $78(39.6 \%)$ \\
No & $31(26.3 \%)$ & $6(3.0 \%)$ \\
Do not know & $12(10.2 \%)$ & 0 \\
Missing & $2(1.7 \%)$ & \\
CYA treatment, $n(\%)$ & & $9(4.6 \%)$ \\
Dialysis at home & $4(3.4 \%)$ & $8(4.1 \%)$ \\
Dialysis in hospital & $12(10.2 \%)$ & $25(12.7 \%)$ \\
Immunosuppression & $10(8.5 \%)$ & $40(20.3 \%)$ \\
No treatment & $28(23.7 \%)$ & $59(29.9 \%)$ \\
Other treatment & $22(18.6 \%)$ & $56(28.4 \%)$ \\
Missing & $42(35.6 \%)$ & \\
\hline
\end{tabular}

themselves $(62 \%)$ or included by parental response $(57 \%)$, were in the shielded group - they recalled receiving a letter or text message from the government. A small number of respondents $(10 \%)$ were unaware if they were shielded or not. There was no perceived difference between the groups in whether they saw their clinical teams less during the lockdown period (shielded $43 \%$ vs. non-shielded 35\%, $p=0.47$ ).

For CYA, significant differences between shielded and non-shielded groups were found in 8 out of 29 (28\%) questions in all domains except support needs. Shielded CYA reported being more vigilant about virus symptoms (76\% vs. $50 \%, p=0.05)$ and kidney symptoms (87\% vs. $55 \%, p=$ $0.009)$, more worried about feeling isolated (55\% vs. $25 \%, p$ $=0.035)$, more likely that isolation brought up negative memories $(73 \%$ vs. $27 \%, p=0.01)$ and felt more protected with shielding advice $(66 \%$ vs. $25 \%, p=0.003)$. Shielded CYA felt that they received adequate information from their clinical teams ( $62 \%$ vs. $5 \%, p<0.001)$, should be isolated (64\% vs. $33 \%, p=0.03$ ) and stated that it was more difficult to adhere to their treatment plans $(22 \%$ vs. $0 \%, p=0.03)$.

For parents, shielded vs. non-shielded group differences were found in 16 out of $32(50 \%)$ questions throughout all domains. To highlight the 7 most significant differences $(p<$ 0.01 ), parents of shielded children were significantly more vigilant about virus symptoms $(90 \%$ vs. $71 \%, p=0.004)$ and worried about their child going outside (67\% vs. $44 \%, p$ $=0.006)$. They reported better information from their clinical teams $(53 \%$ vs. $25 \%, p=0.001)$. In the decisions domain more parents thought their child should be isolated to their immediate families $(64 \%$ vs. $35 \%, p=0.001)$ or just their parents/caregivers ( $41 \%$ vs. $18 \%, p=0.007$ ); they worried more about home visits from nurses/caregivers ( $p=31 \%$ vs. $10 \%, p=0.006$ ) and worried more about the impact on other children in the family $(77 \%$ vs. $47 \%, p=0.002)$.

\section{Qualitative findings from open text questions}

Qualitative open questions contained a total of 1,406 quotes (228 Experiences, 158 Hospital, 165 Positive aspects, 262 Mood, 171 Information, 214 Decision making and 208 Support). There was considerable overlap in answers given, and it was observed that participants, after answering the first question about their Experiences, were repeating their responses in the remaining open questions.

Thematic content analyses with example quotes from the Experiences question are presented in Table 2. Five main themes emerged concerning the virus (risk of infection, information guidance and advice and change in healthcare provision) or about lockdown and isolation (the psychological and social impact and keeping safe). 
Children and Young Adults aged 12-30 years with chronic kidney conditions

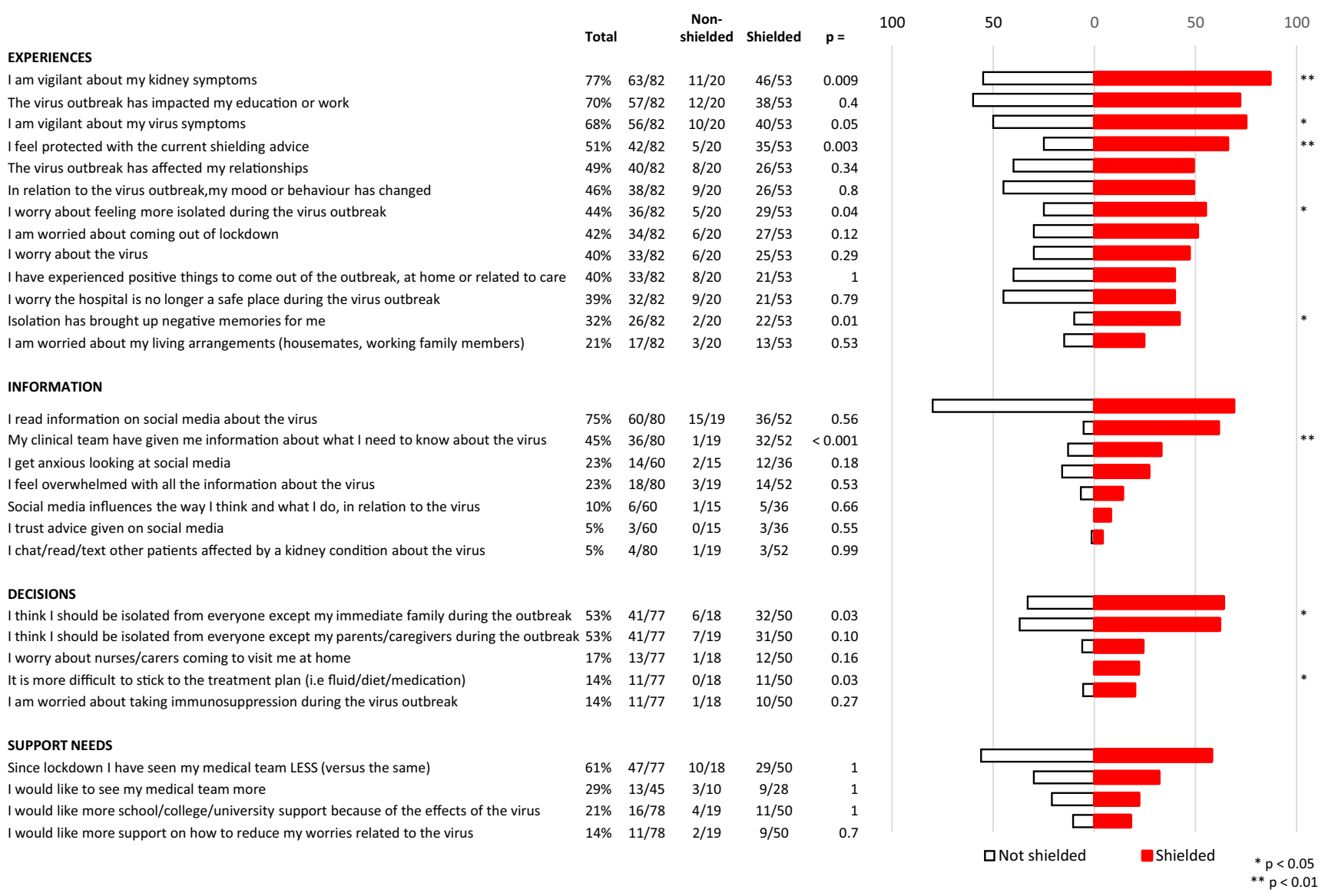

Fig. 1 Children and young adults aged 12-30 years with chronic kidney conditions. Amalgamated responses of those who answered 'quite a bit' or 'very much' to each question

The strongest signal from both CYA $(n=21)$ and parents $(n=65)$ related to the concern that contracting the virus would lead to serious illness and they were taking extra precautions to shield. However, this was not universal; a sizable number of comments from CYA $(n=12)$ and parents $(n=17)$ stated they had no concerns about the virus or had initial concerns which subsided. The predominant comments from CYA $(n=11)$ and parents $(n=14)$ in the information, guidance and advice subtheme, felt they had received only limited information or mixed messages.

When sub-themed by psychological and social impact, CYA $(n=37)$ generated many more comments compared to parents $(n=8)$. The most common comments from CYA was they felt they were missing out on work-related and educational opportunities $(n=14)$, missing family and friends $(n=$ 9) and compared to their peers they lived with more restrictions and were missing out on life $(n=8)$.

In the keeping safe under lockdown subtheme, CYA $(n=$ $7)$ and parents $(n=6)$ were worried about adjusting to life after the lockdown. Several CYA $(n=7)$ were also concerned about the general public not following social distancing and hygiene rules, thus putting everyone at risk.
Findings from the other six open questions are summarised in Table 3 .

\section{Discussion}

This is the first study specifically surveying CYA with kidney conditions and their parents' experience of the COVID-19 pandemic during lockdown. Both CYA and parents were vigilant about the virus and kidney symptoms. Some notable differences exist between the two groups, e.g. CYA worried less about the virus than parents. CYA felt the impact of lockdown most keenly in terms of education and work; parents were particularly worried about their child catching the virus from them and the impact on others at home. Significant differences were found between shielded and non-shielded groups. Information about the virus was gained from multiple sources including social media but they were not always trusted. Free text responses indicated a strong desire for more tailored information to make sensible decisions about their individual risk. We determined that there was a strong sense 


\section{Parents of Children and Young Adults with chronic kidney conditions}

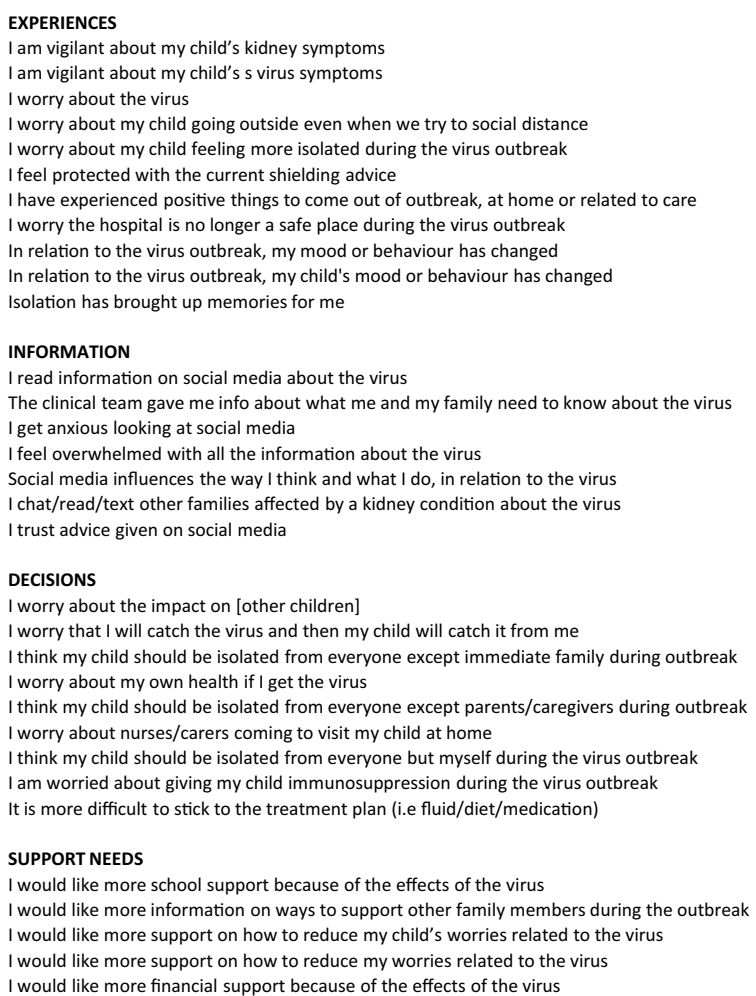

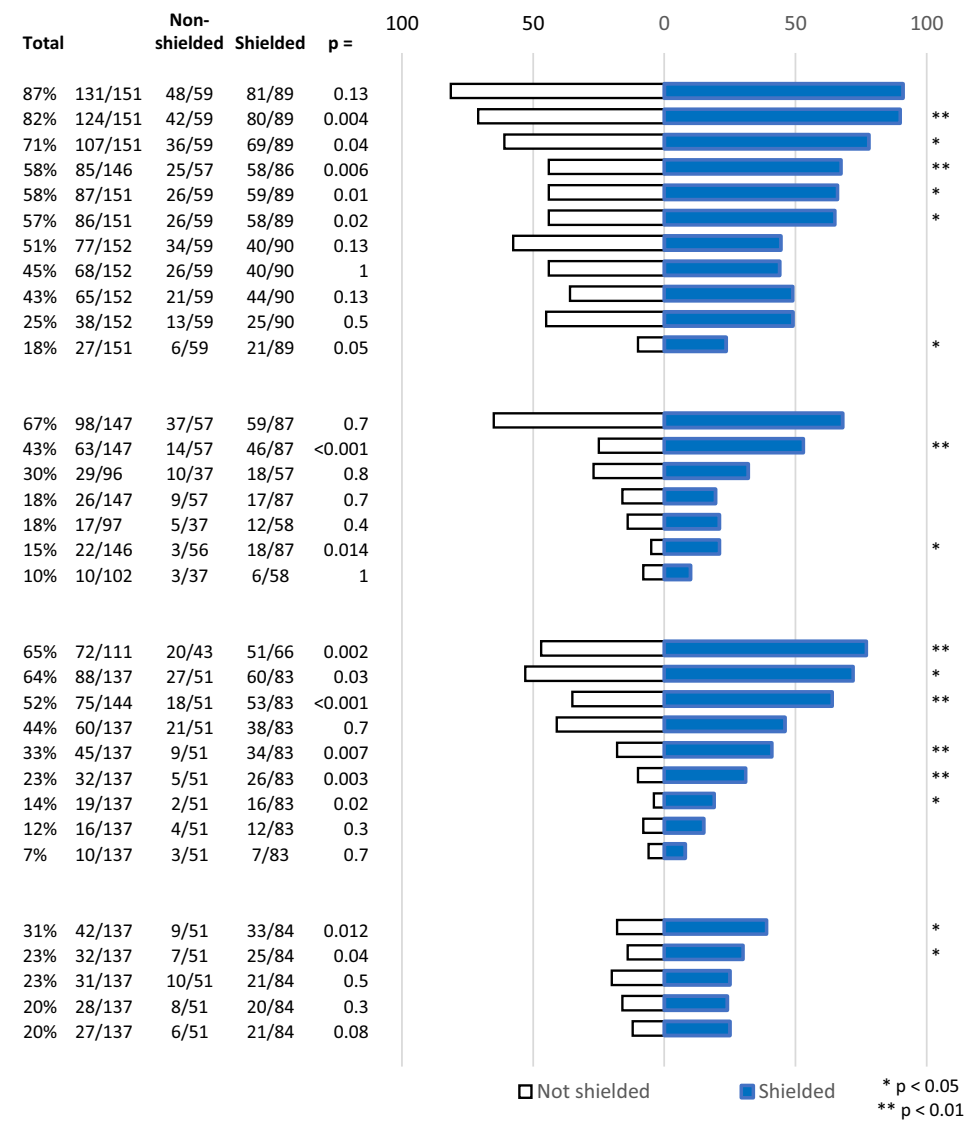

Fig. 2 Parents of children and young adults aged 12-30 years with chronic kidney conditions. Amalgamated responses of those who answered 'quite a bit' or 'very much' to each question

of pragmatism as there was little demand for extra support and decisions were largely based on common sense.

\section{Unique challenges of young people with chronic kidney diseases during COVID}

COVID-19 affected our patient population very differently according to age. Less than five kidney replacement patients out of a cohort of more than 1,000 children in the UK had a positive COVID-19 test up until mid-July 2020, at completion of our study, and none had serious disease [21]. Similar mild outcome was found in a global study of COVID-19 in children on immunosuppression for kidney diseases [22]. Reassuring data is also available for young adults although these subgroups are not usually made explicit [10]. Our study indicates that the majority of CYA and parents base their decisions on 'common sense and what they could reasonably do to protect themselves or their child' and would therefore value further tailored information based on outcome data to make decisions for themselves and their family.

CYA $(42 \%)$ did report being worried about coming out of lockdown (this question was not specifically asked of parents). This alongside already reported psycho-social vulnerabilities in this group indicate a likely need for increased mental health and well-being support [7]. This will be particularly important during the on-going pandemic as CYA and parents adjust to the changing COVID-19 landscape, particularly regarding their risk status and return to school, further education or the workplace. Recommendations from professional groups can also help inform and reassure CYA and parents as they potentially move from being reclassified as 'extremely clinically vulnerable' to being in a 'not at increased risk group' [12]. The positive impact of lockdown on health and well-being should also be evaluated and be reflected in healthcare messages and provisions post-lockdown.

In many countries, specific measures are advised for those thought to be at highest risk; in the UK an estimated 2 million clinically extremely vulnerable people were identified and asked to shield. This is the first study with comparable shielded and non-shielded CYA. Differences in several key domains were found, especially in the parent responses, suggesting the amplification of negative experiences within the shielded group. Both CYA and parents in the shielded group worried about feeling isolated. CYA who were shielded reported feeling 
Table 2 Qualitative findings from open questions under experiences

Theme Subtheme $\quad \frac{\text { Number of quotes }}{n} \frac{\text { Quotes }}{\text { CYA Parent }} \frac{\text { CYA }}{\text { Parent }}$

Virus

Risk of infection

\author{
Concerns over getting ill \\ and taking extra \\ precautions to shield.
}

No concerns about the

virus. Worries initially

but not now.

Concern over visiting hospitals.

Concerns about other family members

contracting the virus.

Concerns about the virus entering the home from an infected family member/parent who is a key worker.

General expression of fear. -

CYA possibly has had/possibly had COVID.
21

65

6 I always look after myself
so no change.

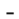

5 virus in the hospital. GFR having dropped cored to my normal, anxiety, especially in the really is knowing the fact if I got it, it would mean most likely another hospital admission.
The only thing that worries me

We started to shield the week before lockdown due to his kidney and heart condition. We became very concerned about the effect covid-19 is having on the kidneys and with our son already having previous problems and bi duplex kidneys we were almost relieved to be told to shield officially.

As she is only at Stage 1 we have not many serious worries. I am very conscious of hygiene and that she drinks her liquids as instructed.

We have stayed home and not been out, apart from hospital visits and a stay. In hospital is terrifying because you know a lot of people have the virus and have been around the virus and not even stick to social distancing. current climate, as I worry about the safety relating to the

My main worry is about my family who have to go to the shops/still work to bring me and my grandparents' food. this is something causing me

As I am still working throughout the lockdown, I worry constantly about contracting the virus and bringing it home to my child and other family members living at home. I work as a customer assistant for Tesco so am in constant contact with other people.

My child is 7 years old. He was diagnosed two years ago is needing twice a week hospital treatment and daily immunosuppression (tacrolimus, MMF, steroids). For us, COVID has exacerbated our child's anxiety and struggles. He has always coped very well despite the demands of his condition, which is incurable and progressive. Since the COVID pandemic, he has struggled with severe anxieties around dying.

It is likely that as a family we caught COVID 19 prior to lockdown (close contact with 
Table 2 (continued)

Theme Subtheme $\quad \frac{\text { Number of quotes }}{\text { CYA Parent }} \frac{\text { Cyotes }}{\text { CYA }}$

Information, guidance and advice

\author{
Limited information/mixed 11 \\ messaging.
}

Need for targeted advice and support.

Good information from hospital staff.

Healthcare provision

4
Delays regarding kidney
transplant operations.

Miss routine monitors, check-ups.
3

My worries are delaying kidney check-ups and the big gaps that are between each appointment during the pandemic.
New ways of working at the hospital.

Concern over (possible or real) change in rules who can visit the child if in hospital and only one parent able to accompany CYA. mother at home.

Unfortunately, she caught the virus and me being vulnerable, even though we kept apart and did my best to clean my areas.

I am unsure what level of vulnerability I am, I tried speaking my doctor but heard nothing back or they do not return my calls.

a confirmed case). The children had a mild cough but were otherwise fine.

No information has been provided for us other than usual government advice.

I feel at the beginning we got very little information from the hospital as to what we needed to do. I have taken all my advice so far from the shielding government advice however, I would like to see more specific advice relating to post transplant patients.

I have absolute trust in my daughter's consultant and have been reassured that she is not at risk because of having kidney disease.

The fact we had a transplant planned which was cancelled due to the virus of course has not been a wonderful experience.

I feel that since the lockdown people like my daughter have been ignored. She was due to have her quarterly check-up approximately 5 weeks ago and was told not to attend the hospital and they would sort something out about having her bloods checked and this still has not happened.

The hospital atmosphere is very He has had a routine hospital different very quiet, clearly taking appropriate procedures to prevent patients getting the virus. visit in the lockdown period and we were impressed with how safe we felt in the hospital setting.

Even further restrictions were put in place and my husband was no longer able to visit. In the following weeks I ended up getting the virus myself and I had to go home to self-isolate (...) When I returned the rules changed quite regularly regarding my husband visiting - I found this quite frustrating as depending on who I spoke to I got a different answer. 
Table 2 (continued)

\begin{tabular}{|c|c|c|c|c|c|}
\hline \multirow[t]{2}{*}{ Theme } & \multirow[t]{2}{*}{ Subtheme } & \multicolumn{2}{|c|}{ Number of quotes } & \multicolumn{2}{|c|}{ Quotes } \\
\hline & & CYA & Parent & CYA & Parent \\
\hline
\end{tabular}

Lockdown and isolation

Psychological and social impact

\author{
Missing out on work \\ related and educational \\ opportunities.
}

14

Missing family and friends. 9 restrictions and missing out on life compared to their peers.

Separation from partners.

Delayed resumption of normality after treatment.

Impractical nature of social 2 distancing
As a student nurse I was offered She is in a new town and a new to opt in to help with the pandemic. Although I am receiving no treatment and just check up, I felt that I was more at risk because of my kidney condition and other health conditions. Therefore, I decided to opt out, which case potentially could impact my degree overall.

Have been unable to visit friends Not being able to see friends and and family including my grandad who is in a care home, so I am worried about him.

I feel very locked out of the world, like an outsider, as I hear about everyone else going to the shops and going on walks shows the world is changing.

I made the decision to change my living arrangements and move back full time to live with my parents, as my dad is retired and my mum has been told she can work from home for as long as I need to shield. I normally split my time between living with my parents, and my partner and his family. It was felt it would be inappropriate to stay with my partner as he works in a school (a key worker), and his mum in a GP surgery (also a key worker). We felt, for this reason, it was safer for me to return home. This has been challenging, emotionally, but we are getting through it

I am also down about having to shield, as after so many years of dealing with lupus and kidney failure, I now have my transplant and feel well, yet must stay away from others to stay well which feels isolating like when I had to dialyse and miss out on my masters nights outs. family and not being able to go to preschool, especially when he is feeling well enough to go. to make some new friends and now that is all back on hold it will be stressful for her starting again. Remote learning is hard at times.$$
-
$$ 
Table 2 (continued)

\begin{tabular}{|c|c|c|c|c|c|}
\hline \multirow[t]{2}{*}{ Theme } & \multirow[t]{2}{*}{ Subtheme } & \multicolumn{2}{|c|}{ Number of quotes } & \multicolumn{2}{|l|}{ Quotes } \\
\hline & & CYA & Parent & CYA & Parent \\
\hline \multirow[t]{6}{*}{ Keeping safe under lockdown } & $\begin{array}{l}\text { Concern once restrictions } \\
\text { are lifted/adjustment } \\
\text { concerns. }\end{array}$ & 7 & 6 & $\begin{array}{l}\text { I am worried about the easing of } \\
\text { the lockdown as my work will } \\
\text { start to make arrangements for } \\
\text { me to come back, my work is } \\
\text { a front line receptionist at a } \\
\text { University so we do have } \\
\text { daily contact with people. I } \\
\text { will have to move back to my } \\
\text { partners if I go back to work } \\
\text { which is another risky } \\
\text { situation as his parents work at } \\
\text { supermarkets so could catch } \\
\text { the virus and give it to me. }\end{array}$ & $\begin{array}{l}\text { We live in a small village so it's } \\
\text { quite easy to isolate and can } \\
\text { still exercise in the garden and } \\
\text { ride bikes. I will probably } \\
\text { be more anxious when we } \\
\text { stop shielding. }\end{array}$ \\
\hline & $\begin{array}{l}\text { Concern over societal } \\
\text { compliance in social } \\
\text { distancing and delayed } \\
\text { lockdown. }\end{array}$ & 7 & - & $\begin{array}{l}\text { I was not too worried to start } \\
\text { with, I kept to social } \\
\text { distancing and handwashing, } \\
\text { but it was other people not } \\
\text { following advice that was } \\
\text { starting to worry me. So now } \\
\text { as much as possible I am } \\
\text { staying indoors as much } \\
\text { as I can. }\end{array}$ & - \\
\hline & $\begin{array}{l}\text { Difficulty securing } \\
\text { provisions (food, } \\
\text { cleaning, medication). }\end{array}$ & 2 & 1 & $\begin{array}{l}\text { I want my tacrolimus to be } \\
\text { available locally at } \\
\text { pharmacies not only hospital. }\end{array}$ & $\begin{array}{l}\text { Extremely difficult to access } \\
\text { delivery for } \\
\text { food/medicines/essentials } \\
\text { due to our rural location and } \\
\text { have become reliant on } \\
\text { charitable help. }\end{array}$ \\
\hline & $\begin{array}{l}\text { Reliance on friends and } \\
\text { family to pick up } \\
\text { provisions. }\end{array}$ & 1 & 1 & $\begin{array}{l}\text { I mainly avoid going out and } \\
\text { since I live with my mom, she } \\
\text { usually does the essential } \\
\text { shopping. }\end{array}$ & $\begin{array}{l}\text { My daughter does have good } \\
\text { friends that live nearby who } \\
\text { are dropping off shopping for } \\
\text { her and picking up her } \\
\text { prescriptions as we live } 2 \frac{1}{2} 2 \\
\text { hours drive away. }\end{array}$ \\
\hline & $\begin{array}{l}\text { Being in lockdown keeps } \\
\text { CYA safe }\end{array}$ & - & 2 & - & $\begin{array}{l}\text { We are very frustrated by the } \\
\text { lockdown but understand why } \\
\text { we need to do it. }\end{array}$ \\
\hline & Priority/lack of priority & 1 & - & $\begin{array}{l}\text { Getting to grips with shielding } \\
\text { and signing up for } \\
\text { government support (mainly } \\
\text { for priority food shopping) } \\
\text { was tricky but luckily Kidney } \\
\text { Care UK put some guidance } \\
\text { together to help once it was } \\
\text { made clearer which category } \\
\text { we fell under. }\end{array}$ & \\
\hline
\end{tabular}

Examples of representative quotes from the subthemes are displayed. $N=$ number of quotes. Numbers do not correspond with the ones provided in the section Qualitative Findings as comments were often broken down and categorised under a number of different themes and subthemes

restricted, not being able to see friends and family, which also led to mood changes such as anxiety and 'feeling depressed'. Similar findings were found in a cohort of Chinese children on kidney replacement therapy during lockdown-11\% of families reported anxiety and $13 \%$ depression [23].
Paradoxically, whilst experiencing negative feelings around isolation, CYA and parents recognised its role in keeping them safe and valued being shielded. This was evident in the findings from the free text responses where CYA reported not being too worried at first, but increasingly feeling 
Table 3 Qualitative findings from remaining open questions
Questions and themes
Hospital: I worry the hospital is no longer a safe place during the virus outbreak
May come into contact with infected patients/staff/visitors
Most likely to catch the virus at the hospital
No social distancing with people not following hygiene rules
Confident that my hospital is taking measures
Not confident that hospitals are taking measures
Avoid going to the hospital unless necessary
Worry I may pass on the virus to vulnerable people

CYA $(N)$

Parents $(N)$

26

(20)

2

Positive aspects: I have experienced some positive things to come out of the virus outbreak

Spending time with family/better relationships with family members

$\begin{array}{ll}37 & 80 \\ 12 & 22 \\ 4 & 11 \\ 1 & 8\end{array}$

Changes in the wider society

Appreciating simple things

Mood: In relation to the virus outbreak, my mood or behaviour has changed, if so in what way?

Mood amongst CYAs and parents-self report

Frustrated/less motivation

$35-41$

More stress and anxiety

More relaxed

Depressed/low mood

Tired of juggling many responsibilities

Motivated

Mood amongst CYAs-parental report

Bored/frustrated

Missing friends

Enjoying positive aspects/adjusting well

Stressed/anxious

Depression/low mood

Change of eating habits

Information: Where do you get information on the virus and what other information may you need?

Source of information

Media

NHS (hospital team/website/GP)

$48 \quad 83$

25

Charities

Social media

Internet-not specified

Family members and friends

Conduct own research/WHO/CDC

Workplace/school

Additional information required

More information on shielding

How virus effects children with CKD

Targeted information from hospital

Statistics of COVID-19 on children with CKD

Length of time lockdown is expected

Advice on those waiting for a transplant

Advice tailored to kidney patients

Efficacy of masks

Help available (financial; shopping)

Decision making: How do you make decisions about looking after yourself/your child in relation to the virus?

Common sense

Deciding to shield

Hospital team/NHS

Government

Own knowledge/family and friends

Decisions are child-led

I do not make decisions

Social media

News

Charities

$\begin{array}{ll}32 & 53 \\ 20 & 26 \\ 9 & 32 \\ 6 & 27 \\ 12 & 19 \\ - & 7 \\ 1 & - \\ 1 & - \\ - & 1 \\ - & 1\end{array}$

Support: What additional support would you like?

No additional support required

$39 \quad 53$

More relevant information/more guidelines for those shielding

Mental health support 
Table 3 (continued)

\begin{tabular}{lll}
\hline Questions and themes & CYA $(N)$ & Parents $(N)$ \\
\hline Support from hospital & 6 & 7 \\
Assistance to adjust to life after lockdown & 1 & 8 \\
Financial/employment/education & 4 & 4 \\
How to keep the child safe & - & 8 \\
Access to literature and relevant data & - & 8 \\
More appointment remotely/access to medication & 1 & 3 \\
Positive news/general reassurance & - & 4 \\
Support with home schooling & 1 & 2 \\
Availability of food delivery slots & 2 & 2 \\
Reassurance about the safety of hospitals & 2 & 2 \\
Testing of family members/PPE at home & & 4 \\
\hline
\end{tabular}

Thematic content analysis distilled the themes. Numbers do not necessary correspond with the numbers of respondents or number of questions as quotes were often broken down and categorised under a number of different themes

$N=$ number of quotes

concerned about other people not following social distancing rules.

\section{Strengths and limitation of study}

This study has several strengths. It is a national study, coproduced with parents and CYA, representing their voices across a wide range of kidney issues during the pandemic. It is the first study that has directly asked children and young adults living with a kidney condition about the effects of COVID-19 and lockdown. Qualitative research can provide valuable insights into patient and parent experiences and inform health care workers about where to target resources. CYA respondents but not parent respondents were ethnically representative of the UK Renal Registry (UKRR) population [24].

Limitations of the study include the contracted time period in which it was necessarily undertaken and the inability to triangulate data between CYA and their respective parent for those $<19$ years or explore themes in depth with targeted interviews or user groups. The self-reporting nature of the survey precluded verification of medical background, treatment, shielding category or adherence to public health recommendations. We did not mandate answers to any of the qualitative or quantitative questions, including shielding categories, resulting in missing data increasingly more prevalent later in the survey. The patients were a heterogeneous group covering the whole spectrum of disease severity. We did not
Table 4 Suggestions to help address gap in information and support needs based on study responses

\begin{tabular}{|c|c|}
\hline Survey respondents feel: & Healthcare team recommendations \\
\hline \multirow[t]{2}{*}{$\begin{array}{l}\text { Lack of information about individualised } \\
\text { COVID risk and shielding information }\end{array}$} & $\begin{array}{l}\text { Shared decision making with kidney team based on } \\
\text { up-to-date data }\end{array}$ \\
\hline & $\begin{array}{l}\text { Develop kidney-specific information with specialists on } \\
\text { charity websites and social media, both for young people } \\
\text { and parents }\end{array}$ \\
\hline \multirow[t]{2}{*}{ Worry about hospital visits } & $\begin{array}{l}\text { Show patients how we have made kidney clinic and } \\
\text { dialysis unit safe }\end{array}$ \\
\hline & Make it easier to obtain medicines \\
\hline \multirow[t]{3}{*}{ Support patients with their worries } & Offer psychological support when needed \\
\hline & Promote peer-support groups \\
\hline & Ask about well-being at consultations \\
\hline \multirow[t]{2}{*}{$\begin{array}{l}\text { Option to contact their kidney } \\
\text { team using technology }\end{array}$} & $\begin{array}{l}\text { Offer video or telephone consultations, and ability to email } \\
\text { or text kidney team }\end{array}$ \\
\hline & $\begin{array}{l}\text { Develop new ways of finding information, e.g. web forums } \\
\text { or online Q\&A }\end{array}$ \\
\hline $\begin{array}{l}\text { Want to build on positive aspects of lockdown } \\
\text { (e.g. peer support, technology, family time) }\end{array}$ & Continue making positive changes even after COVID \\
\hline $\begin{array}{l}\text { Anxiety about emerging from lockdown, } \\
\text { education and workplace }\end{array}$ & Advocating and speaking out for patients \\
\hline
\end{tabular}


measure access to virtual clinics or urban/rural geography which may have influenced respondents' experience of healthcare. The use of social media to distribute and access the study may have also limited access to English-speaking individuals with compatible devices/smartphones [25].

\section{Application of this study}

This study offers clinicians managing chronic disease information about how CYA and parents perceive risk and how they access information and support during a pandemic. The study indicated that CYA and parents want clear tailored information about individual risk from those that they trust, their clinical team, and accessing trusted information via social media is preferred. In a recent analysis only two thirds of cancerrelated social media information was accurate, so debunking COVID-19 misinformation is a challenge for healthcare teams and governments [26, 27]. Improved information and guidance will also be needed to reassure CYA and parents that they can now access healthcare safely. Our suggestion to help address gaps in information and support needs based on study responses is listed in Table 4.

The challenge now will be to keep pace with the fluctuations in virus prevalence and risk, ensure the safe delivery of ongoing care including transplantation and provide support alongside tailored advice to CYA and parents so they can continue to live well during a pandemic.

Supplementary Information The online version contains supplementary material available at https://doi.org/10.1007/s00467-021-05041-8.

Acknowledgements We would like to thank all children, young adults and parents who contributed their time and experiences to this study especially Southampton Children's Hospital patients and families (Thomas Allfree, Alisia Coles, Jack Howe, Amy Kinrade, Madison Parffett, Alisa Braha, Leon Bicknell, Sian Roberts, Sarah Allfree, Angela Kinrade, Lisa Coles, Emma Roberts, Christopher Bicknell) and the Young Adult Kidney Group (Madeleine Warren, Sarah Green, Holly Loughton). We would also like to thank Kidney Care UK (Paul Bristow, Suzan Yianni), Kidney Research UK (Sandra Currie, Aisling McMahon) and the young adult and youth workers who supported the dissemination of the study. Special thanks to colleagues in the Renal Association and British Association for Paediatric Nephrology (including patient representative Kamal Dhesi) and in our units for championing the study, and apologies for any omissions: Alder Hey Children's Hospital Liverpool (Louise Oni, Caroline Jones), Birmingham Children's Hospital (Larissa Kerecuk), Bristol Royal Hospital for Children (Janet Dudley, Lucy Plumb), Evelina London Children's Hospital (Grainne Walsh, Christopher Reid), Great Ormond Street Hospital London (Kjell Tullus, Daljit Hothi), Leeds Children's Hospital (Amanda Newnham), Newcastle Hospital (Lauren Mawn, Helen Ritson), Nottingham Children's Hospital (Andrew Lunn), Royal Belfast Hospital for Sick Children (Mairead Convery), Royal Hospital for Children Glasgow (Ben Reynolds), Southampton Children's Hospital (Caroline Anderson, Rosemary Dempsey, Sarah Shameti, Eleanor Stubbs), University Hospitals
Southampton NHS Foundation Trust and Queen Alexandra Hospital Portsmouth (Kirsten Armstrong) and University Hospital of Wales (Shivaram Hegde).

Data availability statement The data underlying this article will be shared on reasonable request to the corresponding author.

Author contributions All authors were involved in conception and design, drafted the article and approved the final manuscript. SC, ARS, ASD and DC obtained ethics, designed the data collection platform, collected data and performed thematic analysis and statistics. YT, KT, DW, $\mathrm{TP}$ and AN organised the kidney community as stakeholders and to promote the study. AN obtained funding. ASD leads the family of SHARE studies.

Funding We thank Kidney Care UK and Kidney Research UK for funding and publicising the survey. Funders had no part in data collection, interpretation or reporting.

\section{Declarations}

Conflict of interest statement The authors declare no competing interests.

\section{References}

1. Brooks SK, Webster RK, Smith LE, Woodland L, Wessely S, Greenberg N, Rubin GJ (2020) The psychological impact of quarantine and how to reduce it: rapid review of the evidence. Lancet 395:912-920

2. Zhou S-J, Zhang L-G, Wang L-L, Guo Z-C, Wang J-Q, Chen J-C, Liu M, Chen X, Chen J-X (2020) Prevalence and sociodemographic correlates of psychological health problems in Chinese adolescents during the outbreak of COVID-19. Eur Child Adolesc Psychiatry 29:749-758

3. Bakr A, Amr M, Sarhan A, Hammad A, Ragab M, El-Refaey A, ElMougy A (2007) Psychiatric disorders in children with chronic renal failure. Pediatr Nephrol 22:128-131

4. Fukunishi I, Honda M (1995) School adjustment of children with end-stage renal disease. Pediatr Nephrol 9:553-557

5. Kilicoglu AG, Bahali K, Canpolat N, Bilgic A, Mutlu C, Yalçın Ö, Pehlivan G, Sever L (2016) Impact of end-stage renal disease on psychological status and quality of life. Pediatr Int 58:1316-1321

6. Amr M, Bakr A, El Gilany AH, Hammad A, El-Refaey A, ElMougy A (2009) Multi-method assessment of behavior adjustment in children with chronic kidney disease. Pediatr Nephrol 24:341347

7. Hamilton AJ, Caskey FJ, Casula A, Ben-Shlomo Y, Inward CD (2019) Psychosocial health and lifestyle behaviors in young adults receiving renal replacement therapy compared to the general population: findings from the SPEAK study. Am J Kidney Dis 73:194 205

8. Public Health England (2020) Guidance on shielding and protecting people who are clinically extremely vulnerable from COVID-19 (First published 21 March 2020). https://www.gov. uk/government/publications/guidance-on-shielding-andprotecting-extremely-vulnerable-persons-from-covid-19. Accessed 19 February 2021

9. Tse Y, Plumb L, Hulton S, Inward C (2020) Information and guidance for children on haemodialysis, peritoneal dialysis and immune suppression including renal transplants (Updated 20 August 2020). British Association for Paediatric Nephrology. https://renal.org/ 
health-professionals/covid-19/bapn-resources. Accessed 19 February 2021

10. Ravanan R, Callaghan CJ, Mumford L, Ushiro-Lumb I, Thorburn D, Casey J, Friend P, Parameshwar J, Currie I, Burnapp L, Baker R, Dudley J, Oniscu GC, Berman M, Asher J, Harvey D, Manara A, Manas D, Gardiner D, Forsythe JLR (2020) SARS-CoV-2 infection and early mortality of waitlisted and solid organ transplant recipients in England: a national cohort study. Am J Transplant 20:30083018

11. Chen K, Didsbury M, van Zwieten A, Howell M, Kim S, Tong A, Howard K, Nassar N, Barton B, Lah S, Lorenzo J, Strippoli G, Palmer S, Teixeira-Pinto A, Mackie F, McTaggart S, Walker A, Kara T, Craig JC, Wong G (2018) Neurocognitive and educational outcomes in children and adolescents with CKD: a systematic review and meta-analysis. Clin J Am Soc Nephrol 13:387-397

12. Green P (2020) Risks to children and young people during COVID19 pandemic. BMJ 369:m1669

13. Hill R (1998) What sample size is "enough" in internet survey research. Interpersonal Comput Technol 6:1-12

14. Gay LR, Diehl PL (1992) Research methods for business and management. Macmillan, New York

15. Safdar N, Abbo LM, Knobloch MJ, Seo SK (2016) Research methods in healthcare epidemiology: survey and qualitative research. Infect Control Hosp Epidemiol 37:1272-1277

16. Morgan JE, Cleminson J, Stewart LA, Phillips RS, Atkin K (2018) Meta-ethnography of experiences of early discharge, with a focus on paediatric febrile neutropenia. Support Care Cancer 26:10391050

17. Morgan JE, Phillips B, Stewart LA, Atkin K (2018) Quest for certainty regarding early discharge in paediatric low-risk febrile neutropenia: a multicentre qualitative focus group discussion study involving patients, parents and healthcare professionals in the UK. BMJ Open 8:e020324. https://doi.org/10.1136/bmjopen-2017020324

18. Robertson EG, Wakefield CE, Shaw J, Darlington AS, McGill BC, Cohn RJ, Fardell JE (2019) Decision-making in childhood cancer: parents' and adolescents' views and perceptions. Support Care Cancer 27:4331-4340

19. Mason J (2017) Qualitative researching. Sage, London
20. Wagland R, Bracher M, Drosdowsky A, Richardson A, Symons J, Mileshkin L, Schofield P (2017) Differences in experiences of care between patients diagnosed with metastatic cancer of known and unknown primaries: mixed-method findings from the 2013 cancer patient experience survey in England. BMJ Open 7:e017881. https://doi.org/10.1136/bmjopen-2017-017881

21. Plumb L, Benoy-Deeney F, Casula A, Braddon FE, Tse Y, Inward C, Marks S, Steenkamp R, Medcalf J, Nitsch D (2020) COVID-19 in children with chronic kidney disease: findings from the UK renal registry. Arch Dis Child 106:e16

22. Marlais M, Wlodkowski T, Vivarelli M, Pape L, Tönshoff B, Schaefer F, Tullus K (2020) The severity of COVID-19 in children on immunosuppressive medication. Lancet Child Adolesc Health 4:e17-e18

23. Zhao R, Zhou Q, Wang X-W, Liu C-H, Wang M, Yang Q, Zhai YH, Zhu D-Q, Chen J, Fang X-Y (2020) COVID-19 outbreak and management approach for families with children on long-term kidney replacement therapy. Clin J Am Soc Nephrol 15:1259-1266

24. Plumb L, Casula A, Magadi W, Braddon F, Lewis M, Marks SD, Shenoy M, Sinha MD, Maxwell H (2018) UK Renal Registry 20th Annual Report: Chapter 11 Clinical, Haematological and Biochemical Parameters in Patients on Renal Replacement Therapy in Paediatric Centres in the UK in 2016: National and Centre-specific Analyses. Nephron 139:273-286

25. Phares V, Lopez E, Fields S, Kamboukos D, Duhig AM (2005) Are fathers involved in pediatric psychology research and treatment? J Pediatr Psychol 30:631-643

26. Gage-Bouchard EA, LaValley S, Warunek M, Beaupin LK, Mollica M (2018) Is cancer information exchanged on social media scientifically accurate? J Cancer Educ 33:1328-1332

27. Limaye RJ, Sauer M, Ali J, Bernstein J, Wahl B, Barnhill A, Labrique A (2020) Building trust while influencing online COVID-19 content in the social media world. Lancet Digit Health 2:e277-e278

Publisher's note Springer Nature remains neutral with regard to jurisdictional claims in published maps and institutional affiliations. 